\title{
Porous nitrogen doped carbon materials as High-Active Oxygen Reduction Catalysts Derived from Biomass (Corn Stalk)
}

\author{
Weimin Cao ${ }^{1}$, Xiaofei Guo ${ }^{1}$, Chaju Zeng ${ }^{1}$, Chao Yang ${ }^{1}$, Wei Zhou ${ }^{1}$, Qiang Liu ${ }^{2, *}$ \\ ${ }^{1}$ College of Sciences, Shanghai University, No. 99 Shangda Rd., Shanghai 200444, P. R. China \\ ${ }^{2}$ School of Environmental and Chemical Engineering, Shanghai University, No. 333 Nanchen Rd., \\ Shanghai 200444, P. R. China \\ *E-mail: qliu@shu.edu.cn
}

doi: $10.20964 / 2020.07 .04$

Received: 10 January 2020 / Accepted: 21 March 2020 / Published: 10 June 2020

\begin{abstract}
In this study, three catalysts (BC-Zn, BC-HP and $\mathrm{BC}-\mathrm{Na}$ ) were prepared by pyrolyzing corn stalk biomass with $\mathrm{ZnCl}_{2}, \mathrm{H}_{3} \mathrm{PO}_{4}$ and $\mathrm{NaOH}$ acting as activator. We compare and summarize the structure and electrocatalytic activity of these carbon materials for oxygen reduction reaction (ORR). A highperformance doped carbon catalyst (BC-Na) with a BET surface area of up to $1337.27 \mathrm{~m}^{2} \mathrm{~g}^{-1}$ was prepared by using $\mathrm{NaOH}$ as an activating agent. For ORR in alkaline media, BC-Zn exhibited a more negative shift of $-0.42 \mathrm{~V}$ ( vs $\mathrm{Hg} / \mathrm{HgO})$ in contrast to $\mathrm{BC}-\mathrm{HP}(-0.31 \mathrm{~V})$ and $\mathrm{BC}-\mathrm{Na}(-0.31 \mathrm{~V})$. Even though BC-Na showed a negative ORR onset potential $(\mathrm{E}=-0.21 \mathrm{~V})$ in comparison with $\mathrm{Pt} / \mathrm{C}(\mathrm{E}=0.09 \mathrm{~V})$, its current density reached up to $5.72 \mathrm{~mA} \cdot \mathrm{cm}^{-2}$, which is much higher than $\mathrm{Pt} / \mathrm{C}\left(3.25 \mathrm{~mA} \cdot \mathrm{cm}^{-2}\right)$. It is supposed that the excellent electrocatalytic property of BC-Na originated from the combined effect of high specific surface area and $\mathrm{N}$ doping. The low-cost and simple approach used in study provides a straightforward route for the preparation of ORR electrocatalysts from biomass.
\end{abstract}

Keywords: oxygen reduction reaction, catalyst, biomass, activating agent

\section{$\underline{\text { FULL TEXT }}$}

(C) 2020 The Authors. Published by ESG (www.electrochemsci.org). This article is an open access article distributed under the terms and conditions of the Creative Commons Attribution license (http://creativecommons.org/licenses/by/4.0/). 